NISTIR 8371

\title{
Promising Practices for Equitable Hiring: Guidance for NIST Laboratories
}

Elizabeth Hoffman

Heather M. Evans

This publication is available free of charge from:

https://doi.org/10.6028/NIST.IR.8371 


\title{
Promising Practices for Equitable Hiring: Guidance for NIST Laboratories
}

\author{
Elizabeth Hoffman \\ Office of the NIST Director \\ Program Coordination Office \\ AAAS Science and Technology Policy Fellow \\ Heather M. Evans \\ Office of the NIST Director \\ Program Coordination Office
}

This publication is available free of charge from:

https://doi.org/10.6028/NIST.IR.8371

April 2021

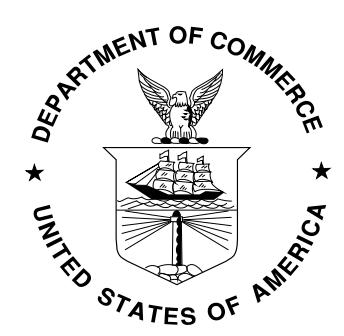

U.S. Department of Commerce

Gina M. Raimondo, Secretary

National Institute of Standards and Technology James K. Olthoff, Performing the Non-Exclusive Functions and Duties of the Under Secretary of Commerce for Standards and Technology \& Director, National Institute of Standards and Technology 
Certain commercial entities, equipment, or materials may be identified in this document in order to describe an experimental procedure or concept adequately. Such identification is not intended to imply recommendation or endorsement by the National Institute of Standards and Technology, nor is it intended to imply that the entities, materials, or equipment are necessarily the best available for the purpose.

National Institute of Standards and Technology Internal Report 8371

Natl. Inst. Stand. Technol. Intern. Rep. 8371, 17 pages (April 2021)

This publication is available free of charge from: https://doi.org/10.6028/NIST.IR.8371 


\title{
Preface
}

In 2020, the Program Coordination Office prepared background information on best practices for hiring of scientists and engineers that use fair and equitable approaches. At the request of the NIST Associate Director for Laboratory Programs, the office presented an overview and recommendations to the Laboratory Directors. This report is intended to make the materials presented in those discussions more widely available to interested staff, especially those involved in hiring decisions at all levels. This research is part of a holistic set of strategic approaches underway at NIST including activities of the NIST Steering Group for Equity in Career Advancement and inclusivity actions encapsulated by the NIST Strategic Plan. This brief report shines light on best practices for equitable hiring, from initial outreach and recruitment to the selection of final candidates, and the value proposition of considering diversity and inclusion in the NIST workforce.

\begin{abstract}
To ensure NIST is taking a strategic and long-term approach to building a diverse workforce, explicit steps should be taken in hiring practices. The best practices described in this report provide a roadmap for Hiring Managers, whether hiring a part-time student researcher or filling a full-time permanent career position. The focus of this report is on practices that target the science, technology, engineering, and math (STEM) workforce at NIST, but they can be extended to other career tracks as well. Using these practices, NIST can achieve greater organizational diversity, improve innovation, and find top talent using evidencebased, effective intervention strategies. The report also provides additional information about the value proposition of diversity and inclusion for productive, innovative workplaces. This report reflects the status of NIST programs and plans as of spring 2021.
\end{abstract}

\section{Key words}

Best practices; Diversity; Hiring; Inclusion; Recruitment; STEM; Workforce. 


\section{Table of Contents}

1. Summary .................................................................................................................... 1

2. Equitable Hiring Practices................................................................................................... 1

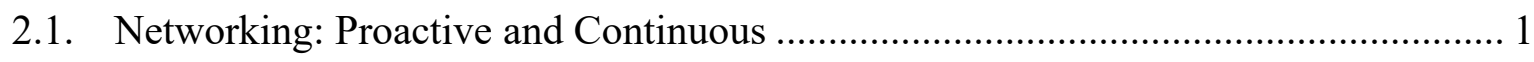

2.2. Job Advertisements: Post Widely.................................................................. 2

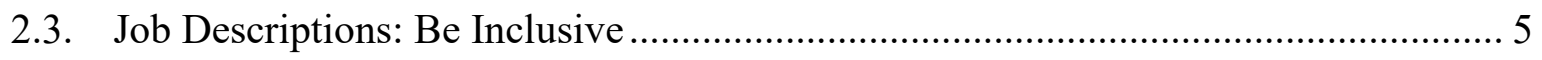

2.4. Application Review \& Interview Process: Be Consistent......................................... 7

3. Benefits of Diverse \& Inclusive Workforces ....................................................................... 9

Acknowledgments .................................................................................................................................. 11

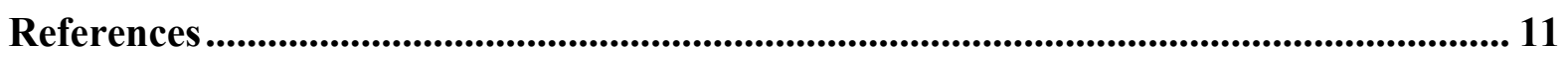

\section{List of Tables}

Table 1. Examples of STEM organizations to expand recruitment networks .......................... 2 


\section{Summary}

The NIST laboratories are fortunate to have a variety of hiring flexibilities at their discretion, including term appointments and direct hire authority for some positions. Overall, these flexibilities are critical for NIST to build and maintain a highly skilled scientific and technical workforce - but we also recognize that they can inhibit a more diverse, equitable workforce if best practices for equitable and fair hiring processes are not employed. Research shows that diverse and inclusive workplaces lead to increased creativity, innovation, and organizational performance [1-3].

To ensure NIST is taking a strategic and long-term approach to building a diverse workforce, explicit steps should be taken in hiring practices to allow NIST to achieve greater organizational diversity and improve representation at every level using evidence-based, effective intervention strategies. Further, these practices can assist with succession planning. Diversity in this context has many facets; it can include demographic diversity (such as age, race, gender, culture, neurodiversity, and disability) as well as experiential diversity (for example, scientific specialty and previous work experience). This brief report highlights promising practices culled from expert reports and leading organizations that should be considered by NIST Hiring Managers.

While many of the practices generalize to any career track, the focus of this paper is on the NIST Laboratory Programs and the hiring of science, technology, engineering, and math (STEM) professionals. After presenting a review of equitable hiring practices, we provide a short overview of some benefits of diverse and inclusive workforces.

\section{Equitable Hiring Practices}

Best practices in hiring can help address equity in the workforce and increase diversity. These practices include engaging in proactive and continuous networking to build talent pipelines, posting job advertisements widely, developing broader and more inclusive job descriptions, and re-examining the applicant review and selection process. The ideas presented here are framed for NIST in the context of findings such as strategies that have been identified to improve faculty hiring in academia [4].

\subsection{Networking: Proactive and Continuous}

Consistently relying on the same networks and word-of-mouth referrals can create a pattern of non-diverse hiring and may inadvertently limit access to skilled candidates. Consider actively networking with people and groups that are likely to lead to diverse talent pools. To be most effective, this should be an ongoing and continuous process and not one that begins only when a position becomes vacant.

Here are some ways to make connections:

- Encourage staff who will be attending professional conferences or universities to combine recruiting with their visits. Individuals could stay connected to NIST through a careers mailing list and also be encouraged to engage with NIST on professional networking sites like LinkedIn to stay up to date on job postings. 
- Attend national student STEM conferences of professional societies and organizations, such as those identified in Table 1. Look for events with successful track records and wide attendance, such as the annual Grace Hopper conference (https://ghc.anitab.org/) that invites participants to "work together to achieve intersectional gender and pay parity in tech." At conferences, give talks and share information on NIST laboratory programs and the broader NIST organization.

- Establish relationships with universities, colleges, departments, etc. in relevant STEM fields that serve a significant number of students from historically underrepresented groups (including gender, sexual orientation, ethnicity, race, first-generation, veteran status, and disability); this can be coordinated through the Academic Affairs Group in the International and Academic Affairs Office.

- Establish relationships with other federal agencies who are successfully recruiting STEM professionals from diverse groups.

- Attend professional conferences, seminars, job fairs, and networking events.

- Provide laboratory tours of facilities to students and teachers/professors of local high schools, colleges, and universities, as feasible.

\subsection{Job Advertisements: Post Widely}

To attract a highly qualified and diverse candidate pool, positions should be advertised widely, both internally and externally. Avoid using the "post and pray" strategy of posting on USAJOBS and hoping qualified candidates find it. Instead, be proactive and go where the talent is by placing targeted advertisements. Here are some strategies:

- Advertise openings in STEM-targeted journals, publications, and with professional organizations. Table 1 provides examples of these organizations but is not exhaustive.

Table 1. Examples of STEM organizations to expand recruitment networks

\begin{tabular}{lll}
\hline Organization & Description & Website \\
\hline $\begin{array}{l}\text { American Association } \\
\text { for the Advancement of } \\
\text { Science (AAAS) }\end{array}$ & $\begin{array}{l}\text { The world's largest multidisciplinary } \\
\text { scientific society and seeks to "advance } \\
\text { science, engineering, and innovation } \\
\text { throughout the world for the benefit of all } \\
\text { people." }\end{array}$ & https://www.aaas.org/ \\
\hline $\begin{array}{l}\text { Annual Biomedical } \\
\text { Research Conference } \\
\text { for Minority Students } \\
\text { (ABRCMS) }\end{array}$ & $\begin{array}{l}\text { One of the largest professional } \\
\text { conferences for underrepresented students } \\
\text { and was "founded to encourage minority, } \\
\text { first-generation, veteran, and disabled } \\
\text { students to pursue higher education in }\end{array}$ & \\
& STEM." & \\
\hline $\begin{array}{l}\text { American Chemical } \\
\text { Society (ACS) }\end{array}$ & $\begin{array}{l}\text { One of the world's largest scientific } \\
\text { organizations with a mission to "advance } \\
\text { the broader chemistry enterprise and its }\end{array}$ & https://www.acs.org/ \\
\hline
\end{tabular}


practitioners for the benefit of Earth and

its people."

\section{American Chemical Society Committee on Minority Affairs}

ACS committee with a mission to "advance a broader, inclusive and equitable chemistry enterprise by empowering underrepresented groups, stakeholders, and marginalized peoples for the benefit of the world."

American Indian
Science and Engineering
Society (AISES)

\section{American Physical Society (APS)}

\section{https://www.chemdiversity.org/}

\section{A "national, nonprofit organization}

focused on substantially increasing the representation of American Indians, Alaska Natives, Native Hawaiians, Pacific Islanders, First Nations and other indigenous peoples of North America in STEM studies and careers."

\section{A nonprofit membership organization} "working to advance and diffuse the knowledge of physics through its outstanding research journals, scientific meetings, and education, outreach, advocacy, and international activities." https://www.aises.org/

A "global network that inspires bold leadership, research, and solutions that advance women in STEM, spark innovation, promote organizational success, and drive systemic change."

\section{https://aps.org/}

ic

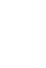

Association for Women
in Science (AWIS)

Minority Postdoc

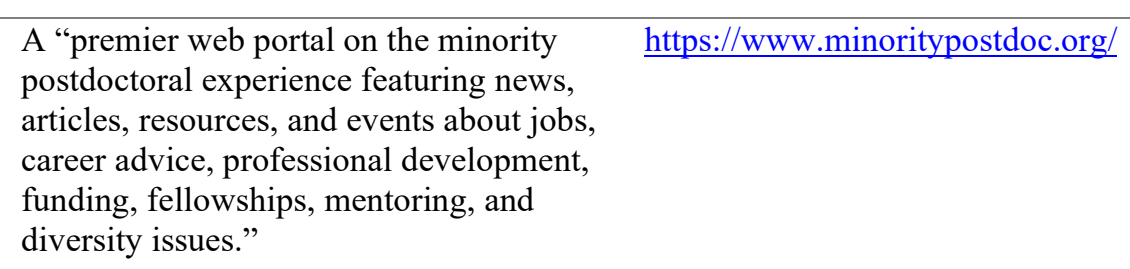

A "premier web portal on the minority

he://wiminoritypostec.org/

National Organization for the Professional Advancement of Black Chemists and Chemical Engineers (NOBCChE)
A non-profit professional organization dedicated to assisting Black and other minority students and professionals in "fully realizing their potential in academic, professional, and entrepreneurial pursuits in chemistry, chemical engineering, and allied fields."

\section{National Society of Black Engineers (NSBE) \\ One of the largest student-governed organizations based in the U.S. with a mission to "to increase the number of culturally responsible Black Engineers who excel academically, succeed professionally and positively impact the community."}

National Society of
Black Physicists (NSBP)

A non-profit organization with the mission to "promote the professional well-being of African American physicists and physics students within the https://www.nobcche.org/

https://www.nsbe.org/ http://www.awis.org/ 
international scientific community and

within society at large."

\begin{tabular}{lll}
$\begin{array}{l}\text { National Society of } \\
\text { Hispanic Physicists } \\
\text { (NSHP) }\end{array}$ & $\begin{array}{l}\text { A society with a purpose to "promote the } \\
\text { professional well-being and recognize the } \\
\text { accomplishments of Hispanic physicists } \\
\text { within the scientific community of the } \\
\text { United States and within society at large." }\end{array}$ \\
$\begin{array}{l}\text { Out to Innovate } \\
\text { (formerly the National } \\
\text { Organization of Gay } \\
\text { and Lesbian Scientists } \\
\text { and Technical } \\
\text { Professionals Inc.) }\end{array}$ & $\begin{array}{l}\text { A professional society and global } \\
\text { community of LGBTQ+ students and } \\
\text { professionals in STEM and their allies. }\end{array}$ & https://www.noglstp.org/ \\
\hline $\begin{array}{l}\text { Society for } \\
\text { Advancement of } \\
\text { Chicanos/Hispanics and }\end{array}$ & $\begin{array}{l}\text { An "inclusive organization dedicated to } \\
\text { fostering the success of } \\
\text { Chicanos/Hispanics and Native } \\
\text { Native Americans in } \\
\text { Science (SACNAS) }\end{array}$ & $\begin{array}{l}\text { Americans, from college students to } \\
\text { professionals, in attaining advanced } \\
\text { degrees, careers, and positions of }\end{array}$ \\
leadership in STEM." \\
\hline $\begin{array}{l}\text { One of the oldest and largest scientific } \\
\text { organizations in the world with a } \\
\text { distinguished history of service to science } \\
\text { and society. }\end{array}$
\end{tabular}

- Post advertisements on job sites such as LinkedIn, Glassdoor, Indeed, etc. (note: USAJOBS automatically pushes notifications to Indeed). The NIST Office of Human Resources Management (OHRM) has up to 10 slots on LinkedIn to post job advertisements - hiring managers can work through their HR specialist to learn more. Further guidance about advertising vacant positions is on the OHRM section of the NIST INET.

- To help announcements reach a broad candidate pool, staff can share USAJOBS/LinkedIn postings on their own social media, in particular to the STEM communities in which they are active. NIST community groups can also be a resource for reaching a wide range of candidates. A list of groups can be found online at https://www.nist.gov/diversity-inclusion-and-equity.

- Send advertisements to universities, colleges, departments, companies, etc. in which qualified candidates from underrepresented groups may be found, if known. This can also include sending job advertisements to faculty/investigators known to have a history of mentoring underrepresented students, or who have received awards and other commendation for their activities in this area.

- Suggested resources for identifying potential early-career candidates include recipients of programs such as the MOSAIC K99/R00 Award; 
Burroughs Welcome Post-doctoral Enrichment Program; Howard Hughes Medical Institute Hanna H. Gray Fellowship; AAAS Science and Technology Policy Fellowship; and the Ford Foundation Fellowship.

- Academic departments that are associated with ADVANCE (https://www.nsf.gov/crssprgm/advance/) and the INCLUDES National Network (https://www.includesnetwork.org/), among other NSF-funded programs that support underrepresented communities in STEM, are a good resource.

- The minority affairs or diversity and inclusion committees of scientific societies (see Table 1 for some examples) are another valuable resource.

- Invite people to apply! Hiring Managers are permitted and encouraged to actively recruit for their open positions. Public notice, or simply posting a job announcement, is not a substitute for more focused recruiting. Strategic recruitment can focus your efforts in areas most likely to yield results and does not violate merit system principles.

- Use LinkedIn Recruiter, which is available on a pilot basis in 2021 and is being evaluated for longer-term use by OHRM. Many federal agencies and private sector companies use LinkedIn Recruiter to search for talent and contact candidates about job openings; the tool offers Hiring Managers extensive search capabilities to network and find candidates.

- Post all positions (both internally and externally, if applicable) to ensure candidates are aware of all possible opportunities, regardless of whether direct hire authority is used.

Ideally, the outreach and other practices used by hiring managers should be recorded to track progress and lessons learned. Data would include where the advertisement was placed, how many contacts were reached outside the hiring manager's own networks, etc. However, given the sensitivity of some of this data, NIST will need to develop additional guidance to clarify expectations and methods of tracking these steps, including who should be responsible for retaining the information.

\subsection{Job Descriptions: Be Inclusive}

How the position is described, including the requirements of the position and the scope of work, should be as inclusive as possible. Represent the organization, program, and position in terms that make evident how it might appeal to a broad range of applicants. Past experiences of other STEM-relevant organizations reveal that language choices do matter. For example, language was one of many changes implemented by NIH when they launched a Director's Pioneer Award for innovative research in 2004 that selected nine men and no women in its inaugural year; six women were among the thirteen awardees in the second year after changes were implemented [5]. Other evidence indicates that the length of the job posting can make a difference, as well. As noted by Google in their 2020 Annual Diversity Report, the firm found a measurable increase in women applicants when job qualifications summaries were less than 54 words [6].

Some tips for more inclusive job descriptions, many from a recent National Academies report [7], include: 
- Avoid describing the position and minimum qualifications so narrowly that it deters candidates from applying.

- Carefully consider what qualifications are minimally required vs. preferred in order to place minimal constraints on requirements and prevent applicants from self-selecting out.

- Examine job requirements to assess their vulnerability to bias, ability to accurately indicate talent (e.g. relying on biased standardized tests), and importance for success.

- Are the characteristics of current employees, students, or leaders the only or best characteristics needed for success?

○ Consider the "backlash effect," where characteristics seen as positive in men are viewed as negative for women by both men and women, and how those play out for race and gender.

- Use gender-neutral terms and avoid descriptors traditionally associated with particular genders. Programs like Textio can help identify biased language in position descriptions.

○ Words and phrases like "is a natural leader," "can succeed in a competitive environment," and "rockstar" are typically associated with men, while "nice," "collaborative," and "supportive" are typically associated with women.

○ Avoid extreme modifiers like "unparalleled," "world-class," and "perfectionist;" replace "innovative" with "creative" and "exceptional" with "motivated."

- Use concise and plain language. A resource for plain language is https://www.plainlanguage.gov/.

- Signal to all candidates that they will be evaluated based on qualifications, not demographic characteristics, by pointing them to resources such as https://www.nist.gov/careers that mention a range of workforce attributes, such as:

- Specific values that support diversity (an equity or inclusion statement can also be included)

- Fair and inclusive recruitment and hiring procedures

- Family-friendly workplace policies for employees and associates

- Sensitivity to concerns about community diversity by providing information on the surrounding area, the history of the area, demographic data, and local activities

While there are some elements that are required for a federal job posting and cannot be modified, additional guidance from management and OHRM can assist Hiring Managers in identifying and using intentionally inclusive language wherever possible. A new online tool, Textio, is being piloted by OHRM starting in May 2021 to assist Hiring Managers in drafting this language, and job description templates developed using Textio are available from OHRM. 


\subsection{Application Review \& Interview Process: Be Consistent}

When reviewing candidates, consistency is a hallmark of equitable hiring practices. The suggestions below involve guidance for NIST Hiring Managers and for others involved with interviewing and ranking potential candidates, building off of many resources including the Bias Interrupters organization's tips to identify bias in hiring [8].

- Use a panel to interview multiple referred candidates for every open position.

- Even if there is a preferred candidate for a position, the Hiring Manager should interview more than one candidate (as a general practice, 3-5 are recommended) to promote fair and open competition. This should apply for all federal positions regardless of hiring authority used.

- Build a diverse selection panel (e.g., gender, race, age, background, organizational role).

- Members of this panel should be supportive of hiring and retention of underrepresented groups (equity advocates) and be well-versed in the specific position requirements.

- Be respectful of the time commitment of panel members who contribute to the diversity of the panel by not repeatedly requesting the participation of the same individuals.

- Recognize and mitigate bias in the interview panel and interview process. For example:

- Bias mitigation education with evidence-based strategies has the potential to create change in hiring practices. A National Academies report recommends holding practice-oriented trainings with panel members prior to the interviews to share evidence of implicit bias in hiring and offer stereotype-challenging strategies shown to improve workplace climate and representation in hiring [7]. Relevant online trainings are available for NIST staff in the Commerce Learning Center (CLC, https://doc.csod.com/client/doc/), for example "Understanding Unconscious Bias" and "Overcoming Unconscious Bias in the Workplace."

- Interviewers should be sensitive when considering employment "gaps" in a resume.

- Resume gaps can arise in many ways and immediately dismissing them as disqualifying can inappropriately limit the applicant pool. Bias against parents is not only limited to women; in one study men who requested parental leave were viewed as weaker, poorer workers and less deserving of economic rewards [9].

- Re-think how scientific work is assessed.

- Consider asking candidates about how their research has helped address important questions in their fields to evaluate their ability to discuss these topics in an accessible manner rather than relying on the perceived pedigree of their publications to assess scientific importance.

○ Consider skills beyond the bench that further scientific progress (e.g., mentoring, involvement with diversity and inclusion work).

- Establish evaluation criteria (quantifiable and qualifiable) before assessing an application pool and follow them throughout the hiring process. 
○ Define terms such as "excellence" and "impact" and determine beforehand how they will be applied and evaluated.

- If criteria are waived for an applicant, this should be documented, explained, and tracked.

- Use a reviewer form for each evaluator/panel member that requires them to assess and score each candidate against the same the criteria to ensure consistency.

- Use a structured interview process, such as outlined by the Office of Personnel Management [10].

- Ask all candidates the same performance-based or behavioral interview questions - these answers are strong predictors of success and prevent relying on perceived "potential."

○ Provide the same information to all applicants (i.e., do not only provide childcare information to women).

○ If "culture fit" is used as criteria for the evaluation of candidates, this must be well-defined. Alternatively, think of the "culture add" of a candidate instead of "culture fit."

○ Be prepared to discuss NIST's inclusivity activities and overall climate. Even if questions do not come up, the information should be shared with candidates to illustrate NIST's commitment to inclusivity.

- Do not ask inappropriate questions during the interview. OHRM can provide additional details and guidance on this topic.

- Do not ask questions or make comments about the applicant's age, sex, race, national origin, marital or familial status, disabilities or health status, criminal status, religious affiliation, salary history, or any other job-irrelevant factor.

○ Note: Federal law prohibits Hiring Managers from asking candidates these questions.

- Effectively communicate with all candidates and ensure equal opportunity for all candidates. Do not label one candidate as the "most promising" until all candidates have been considered.

- Document your interview/selection process and consider sharing evaluation templates and interview questions with colleagues to help encourage the use of these best practices. 


\section{Benefits of Diverse \& Inclusive Workforces}

The evidence is mounting that diversity, inclusion, and equity in the workplace is simply the right thing to do and is also a benefit to organizations.

"Diversity in the workplace is an asset for both businesses and their employees, in its capacity to foster innovation, creativity and empathy in ways that homogeneous environments seldom do. Yet it takes careful nurturing and conscious orchestration to unleash the true potential of this invaluable asset."

-Vijay Eswaran, Executive Chairman QI Group of Companies [1]

Several reports provide evidence that performance increases when diversity is valued in an organization, and employees are more engaged when inclusion and diversity are valued and modeled. Four key themes are increased success, organizational performance, innovation benefits, and attracting - and retaining - talented employees:

1. A McKinsey report [2] found a statistically significant relationship between a more diverse leadership team and better financial performance, indicating that companies who have more diverse teams find more success in their field.

- The companies in the top quartile of gender diversity were $15 \%$ more likely to have financial returns above their national industry median.

- Companies in the top quartile of racial/ethnic diversity were $35 \%$ more likely to have financial returns above their national industry median.

- Companies in the bottom quartile for both gender and ethnic/racial diversity were $25 \%$ less likely to achieve above-average financial returns.

2. When employees feel that their organization is committed to and supportive of diversity, and they feel included, employees report better business performance, as described in a Deloitte study [3]:

- When employees feel that their organization is committed to and supportive of diversity, and they feel included, they are $80 \%$ more likely to believe they work in a high-performing organization, compared to employees that feel their organization is not supportive or committed to diversity and they feel excluded. The business outcomes of having high diversity and low inclusion or low diversity and high inclusion are both lower than the dual combination of high diversity and high inclusion.

- The combination of diversity and inclusion leads to engagement. The highest levels of engagement come from workplaces with a combined focus on diversity and inclusion, compared to engagement in workplaces with high inclusion and low commitment to diversity $(67 \%)$ or high diversity and low levels of inclusion (20\%).

- The more included an employee feels, the more likely they are to be at work, thus reducing the cost of absenteeism, and these employees receive a higher performance rating. The data from one organization indicated that if just $10 \%$ 
more employees feel included in the workplace, the company will increase work attendance by almost one day per year (6.5 hours) per employee.

3. Innovation benefits from diversity are wide-ranging.

- Increased creativity is another asset of embracing differences. The U.S. Office of Personnel Management website www.opm.gov/policy-dataoversight/diversity-and-inclusion/ identifies several examples of diversity and inclusion's benefits, from the Renaissance period of growth spurred by people from the East and West meeting to the catalytic role of immigrants in America's innovation culture, as well as inventions designed by and for individuals with disabilities.

- Having employees with varied backgrounds is a benefit to organizations, as it brings different perspectives, ideas and solutions that lead to new products and services, challenges to the status quo, and new collaboration and partnerships.

- Companies with more diverse management teams have $19 \%$ higher revenues due to innovation, according to a Boston Consulting Group study [11]. The findings are the result of a survey of more than 1,700 companies located in eight countries, including the U.S.

- Singapore provides a case study in the connection between diversity and increased innovation: with a population of over five and a half million, this small South-East Asian island nation with a diverse and multicultural population is one of the leading global financial centers, leads internationally in mathematics and science education [12], and ranks high on many lists of entrepreneurial, energy efficient, and business-friendly nations [1].

- Diverse teams produce better outcomes precisely because it is harder than working on a homogenous team, as described in a Harvard Business Review article titled "Diverse Teams Feel Less Comfortable - and That's Why They Perform Better" [13]. Moreover, researchers recently published a study testing this hypothesis among stakeholders in a fishery community, showing that the mixed group of stakeholders produced better outcomes [14].

4. Organizational diversity and inclusion are needed to attract and retain talented employees.

- We are potentially missing out on the next great innovators. The National Science Board Vision 2030 report identifies "missing millions" of potential STEM workers that will be needed in the future, more than double the number of women and Black workers and triple the number of Hispanic or Latino workers in the STEM workforce today [15].

- Workers value diverse and inclusive workplaces. A February 2021

Washington Post article cites the experiences of many job seekers and findings from industry surveys that confirm the workplace's commitment to inclusion matters [16]. 


\section{Acknowledgments}

The authors appreciate the input and advice of staff in many offices with equities in the NIST workforce including the International and Academic Affairs Office, Civil Rights and Diversity Office, Office of Human Resource Management, and the Associate Director of Laboratory Programs. We are grateful for fruitful discussions with colleagues in the Program Coordination Office, in particular Jason Boehm, Anna Sberegaeva, Kate Rimmer, Kristen Greene, and Bill Healy.

\section{References}

[1] Eswaran V (2019) The business case for diversity in the workplace is now overwhelming, posted 29 April 2019. https://www.weforum.org/agenda/2019/04/business-case-for-diversity-in-theworkplace/ (Accessed April 21, 2021).

[2] McKinsey \& Company (2015) Diversity Matters. https://www.mckinsey.com/ /media/mckinsey/business $\% 20$ functions/organization/our $\% 20$ insights/why\%20diversity\%20matters/diversity\%20matters.pdf (Accessed April 21, 2021).

[3] Deloitte Australia and the Victorian Equal Opportunity and Human Rights Commission (2013) Waiter, is that inclusion in my soup? A new recipe to improve business performance. https://www2.deloitte.com/content/dam/Deloitte/au/Documents/humancapital/deloitte-au-hc-diversity-inclusion-soup-0513.pdf (Accessed April 21, 2021)

[4] Bhalla N (2019) Strategies to improve equity in faculty hiring. Molecular Biology of the Cell 30(22): 2744-2749. https://doi.org/10.1091/mbc.E19-08-0476

[5] Novak K (2005) Complaints of gender bias compel NIH to revise awards scheme. Nat Med 11, 912. https://doi.org/10.1038/nm0905-912b

[6] Google, 2020 Diversity Annual Report https://diversity.google/annual-report/ (Accessed April 21, 2021).

[7] National Academies of Sciences, Engineering, and Medicine. (2020) Promising Practices for Addressing the Underrepresentation of Women in Science, Engineering, and Medicine: Opening Doors. Washington, DC: The National Academies Press. https://doi.org/10.17226/25585.

[8] Bias Interrupters (2016) Bias Interrupters for Hiring \& Recruiting: Identifying Bias in Hiring Guide. https://biasinterrupters.org/wp-content/uploads/Identifying-Bias-inHiring-Guide-no-citations.pdf (Accessed April 21, 2021).

[9] Rudman L and Mescher K (2013). Penalizing men who request a family leave: is flexibility stigma a femininity stigma? Journal of Social Issues 69(2):322-340. $\underline{10.1111 / \text { josi.12017 }}$ 
[10] U.S. Office of Personnel Management. Structured Interviews presentation available online: https://www.opm.gov/policy-data-oversight/assessment-andselection/structured-interviews/structured-interviews.pdf (Accessed April 21, 2021).

[11] Lorenzo R, Boston Consulting Group (2018) How diverse leadership teams boost innovation. https://www.bcg.com/en-us/publications/2018/how-diverse-leadershipteams-boost-innovation (Accessed April 21, 2021)

[12] Rotermund S (2019) Elementary and Secondary Mathematics and Science Education, National Science Board Science and Engineering Indicators.

[13] Rock D (September 22, 2016) Diverse Teams Feel Less Comfortable - and That's Why They Perform Better. https://hbr.org/2016/09/diverse-teams-feel-lesscomfortable-and-thats-why-they-perform-better (Accessed April 21, 2021)

[14] Aminpour P, Gray SA, Singler A, Scyphers S, Jetter A, Jordon R, Murphy R, Grabowski JH (2021) The diversity bonus in pooling local knowledge about complex problems. PNAS 118(5) https://doi.org/10.1073/pnas.2016887118

[15] National Science Board (2020) Vision 2030. Report \# NSB-2020-15. https://www.nsf.gov/nsb/publications/2020/nsb202015.pdf (Accessed April 21, 2021)

[16] Miller J. For younger job seekers, diversity and inclusion in the workplace aren't a preference. They're a requirement. The Washington Post, published Feb. 18, 2021. https://www.washingtonpost.com/business/2021/02/18/millennial-genz-workplacediversity-equity-inclusion// (Accessed April 21, 2021) 